\title{
A propósito del cólera: Max von Pettenkofer y su Experimentum crucis
}

\author{
WALTER LEDERMANN D.*
}

\author{
In connection with Cholera: Max von Pettenkofer and his \\ Experimentum crucis
}

\begin{abstract}
El descubrimiento por Robert Koch del Vibrio comma en 1884 ni señala el comienzo de la historia del cólera ni pone término a las discusiones sobre su patogenia: Koch encontraría en Max von Pettenkofer un obstinado y quizás no tan equivocado adversario, capaz de arriesgar su propia vida en un experimentum crucis y de continuar luchando después de muerto a través de su fiel discípulo Emmerich, a quien un autor moderno ha llamado, con no poco desenfado, "la mano muerta de Pettenkofer".

John Snow fue el primero en postular que las aguas servidas eran el vehículo transmisor del cólera, cuando en el otoño de 1848 llegó a Londres el vapor alemán Elba, procedente de Hamburgo, diseminó este mal a lo largo de la ribera del Támesis. Su primera publicación apareció en 1849 y tanto su precisión, la lógica de su discurso y la belleza de algunas frases, así como las decididas acciones del autor, por sí solas merecen otro artículo: por ahora, ocupémonos de von Pettenkofer.
\end{abstract}

Dos meses después de la primera publicación de Snow, otro célebre epidemiólogo de la época, William Budd, concordaba con sus afirmaciones y le cedía gentilmente la prioridad en el descubrimiento de "este inequívoco mecanismo de transmisión". Y, en efecto, en el mismo número de Lancet en que Snow revisa su primer artículo (octubre 6, 1849), aparece la carta de Budd Alleged discovery of the cause of cholera, en que describe sus propias observaciones de peculiar microscopic objects en las deposiciones de los enfermos. Budd observó estos objetos microscópicos en las fuentes de agua de los distritos afectados por el cólera, pero no en las "saludables" aguas de los sectores libres de la plaga. Esto daría a William Budd la prioridad como descubridor del agente etiológico, precediendo en cinco años al italiano Filippo Pacini, quien los observaría en el intestino de los enfermos recién en 1854. Ambos investigadores no pudieron o no intentaron aislar e identificar los microbios que vieron, perdiendo los "derechos de autor" por falta de una adecuada descripción. El punto es: ¿conocían Koch y sus competidores franceses estos precedentes, cuando viajaron a Oriente a cazar el vibrión?

Pettenkofer conocía los trabajos de Snow y de Budd, concordando con ellos en las virtudes del agua pura, libre de contaminación fecal, tanto es así que fue el principal impulsor de la campaña para traer agua limpia de las montañas a la ciudad de Munich, demostrando a raíz de esta gestión un descenso en la morbo-mortalidad por fiebre tifoidea. Refiriéndose a los trabajos de Snow, concluía que "nadie en su sano juicio puede negarlos". Pero, en el caso específico del cólera, parecía tener sus dudas y quiso convencerse por sí mismo, cosa que nunca lograría. En 1854, con ocasión del brote de Munich, hizo extensos estudios, que publicó un año después en un voluminoso libro de 371 páginas en letra gótica. Pese a encontrar diferencias entre las dos fuentes de agua disponibles, la federal y la estatal, así como analizar en forma exhaustiva los casos originados por la polución del río Isar, concluyó que sus experiencias no bastaban para demostrar la transmisión directa del cólera a través del agua. Faltaba un paso: el contacto con la tierra. Nació así su famosa Bodentheorie, la teoría del suelo. De acuerdo a ella, el germen del cólera, venido de India y aún no identificado, al cual llamó "x", debía unirse a un substrato o factor "y", presente en el suelo bajo ciertas condiciones témporo-espaciales. La suma del binomio $(x+y)$ era igual a " $z$ ", el verdadero "veneno colérico", siendo los dos factores inofensivos por separado. En la Tercera Conferencia Sanitaria Internacional, celebrada en 1866 en Constantinopla, su teoría predominó y ganó la unánime aprobación de los presentes: el aire era el principal vehículo del principio generativo (la miasma colérica $\mathrm{x}+\mathrm{y}=\mathrm{z}$ ) del cólera, deponiendo "de una vez por todas", según sus enérgicas palabras, la idea de una epidemia diseminada por el agua de beber. Con el tiempo su teoría evolucionaría, incluyendo también la tifoidea y otras "enfermedades del suelo" y derivando en la misma tríada epidemiológica: agente $(\mathrm{x})+$ medio ambiente (y) = huésped susceptible $(\mathrm{z})$.

En 1883, el cólera llegó a Egipto y franceses y alemanes viajaron a Alejandría en busca del agente etiológico. Los primeros, infortunados, perdieron al joven Thuillier, víctima del incontenible mal que había ido a combatir; los segundos, encabezados por Gaffky, regresaron en triunfo a Berlín con el Vibrio comma en 1884. Para demostrar su identidad con el cólera asiático, Koch viajó a India, donde obtuvo la ansiada confirmación y pudo adjudicarse legítimamente la autoría del descubrimiento. El Kaiser lo recibió en especial audiencia, concediéndole la Orden del Trono, Segunda Clase, con Estrella. 
Impresionante para todos, pero no para von Pettenkofer: " El descubrimiento del bacilo comma no altera nada y, como es bien sabido, no era inesperado para mí, pues sólo es el factor equis". Diez años después aún se burlaría de los "celosos commacazadores".

Pettenkofer no estaba solo en su lucha: científicos de la talla de Sir Charles Sherrington, Premio Nobel de Medicina 1932, quien en 1885 participara en una misión para estudiar el cólera en España, concluyó que el bacilo comma no era la causa de la enfermedad, concordando con los resultados de una misión similar enviada a India el año anterior, en tanto que un profesor de Oxford, John BurdonSanderson, calificaba el descubrimiento de Koch como "un desafortunado fiasco" en el British Medical Journal (1885; 1: 1076). Por ese año, a juicio de algunos distinguidos observadores, Pettenkofer era "la mayor autoridad viviente sobre la etiología del cólera".

Koch, sin embargo, ganaba adeptos a la par que crecía su prestigio y la bacteriología progresaba como disciplina científica. El enfrentamiento decisivo llegaría con la nueva y terrible epidemia que azotaba Hamburgo en 1892. El ya anciano Pettenkofer (74 años) se vio empujado hacia su famoso experimentum crucis: el 7 de octubre, en presencia de selectos testigos, tras neutralizar su $\mathrm{pH}$ estomacal con bicarbonato, ingirió $1 \mathrm{ml}$ de un caldo de cultivo de vibrión colérico proveniente de un paciente recién fallecido. Se ha estimado que, como lo sostuvo también el porfiado sabio, el trago contenía mil millones de bacilos, pero... ¡oh, sorpresa!... Pettenkofer no murió, experimentando sólo borborismo y una ligera diarrea, demostrando así que al factor " $\mathrm{x}$ " ingerido le había faltado " mi factor y". Sus deposiciones fueron cultivadas, recuperándose el vibrión en cultivo puro. Si hubiera muerto, sostuvo Pettenkofer, "lo habría hecho en servicio de la ciencia, como un soldado en el campo de honor... La salud y la vida son, como a menudo lo he dicho, muy grandes bienes terrenales, pero no los más altos para el hombre. Este, si quiere elevarse sobre los animales, debe sacrificar vida y salud por los más altos ideales".

Por desgracia para su experimentum crucis, dos de sus más leales discípulos que le acompañaron en el peligroso brindis no salieron tan bien parados: Emmerich estuvo yendo al baño "cada hora durante dos días", proporcionando a Koch la ocasión de decir que tanto Pettenkofer como Emmerich habían, verdaderamente, tenido cólera. La réplica del porfiado fue desdeñosa: "Me alegro de proporcionar a mis adversarios este placer, pero no puedo aceptar, so- bre bases epidemiológicas, que $\mathrm{x}+\mathrm{z}$ basten para una epidemia de cólera, en ausencia de y".

Nueve años más tarde, en 1901, al llegar la noche sabatina de su cumpleaños número 83, von Pettenkofer se voló los sesos con una pistola, pero aún habría de alzarse su fantasma frente a Robert Koch con ocasión del brote de tifoidea de Gelsenkirchen.

Max von Pettenkofer no era ningún loco o mentecato. Sus contribuciones en química, fisiología e higiene fueron numerosas y valiosas; su pensamiento, lúcido; su Bodentheorie de manera alguna insensata. ¿Una locura beber un cultivo de cólera? Pues, sorpréndanse: en este siglo, en 1971, Hornick y colaboradores, de la Universidad de Maryland, publicaron sus experimentos cruciales en voluntarios, que bebieron hasta 10 elevado a 11 Vibrio cholerae, aunque no neutralizaron su acidez gástrica con bicarbonato, en tanto que, en 1966, Benyajati le dio toxina colérica a dos voluntarios.

El sabio alemán contó con admiradores hasta nuestros días. En Chile, el profesor Garcés, un microbiólogo genial, pero tímido y modesto, llevaba algunos años observando unas curiosas formas bacterianas, cuyas fotografías tengo a mi lado mientras escribo. En su sencillez, creyó mucho atrevimiento publicar unas observaciones que estimó intrascendentes; Klineberger-Nobe1 se le adelantó y las bautizó como formas $\mathrm{L}$, en indirecto honor a Lister. Si el doctor Garcés hubiese sido más osado, hoy se conocerían con el nombre que familiarmente les daba: "pettenkofereas". Las formas L serían hoy formas P, por el tenaz von Pettenkofer... ¡Gloria a los ilustres pioneros!

\section{Bibliografía}

1.- Snow J. On continuous molecular changes, more particularly in their relation to epidemic diseases (Reproduction). Rev Infect Dis 1985; 7 (3): 441-7.

2.- Bulloch W. History of asiatic cholera. In: A System of Bacteriology in relation to Medicine. HIS Majesty Stationery Office, London 1929; 4: 338-40.

3.- Howard-Jones N. Gelsenkirchen typhoid epidemic of 1901. Robert Koch and the dead hand of Max von Pettenkofer. Br Med J 1973; 1: 103-5.

4.- Hornick R, Music S, Wenzel R et al. The Road Street pump revisited: response of volunteers to ingested cholera vibrios. Bull N Y Acad Med 1971; 47 (10): 1181-91.

5.- Zanca A, Pogliano C, Sironi V, Dulbecco R. Il farmaco nei tempi. Dal laboratorio all'industria. Farmitalia Carlo Erba, Tornasole comunicazione, Pesaro 1989; 8-9. 